\title{
Object-based inhibitory priming in preview search: Evidence from the "top-up" procedure
}

\author{
MELINA A. KUNAR \\ Brigham and Women's Hospital, Cambridge, Massachusetts \\ and \\ GLYN W. HUMPHREYS \\ University of Birmingham, Birmingham, England
}

\begin{abstract}
Visual search in a conjunction task can be facilitated if half the distractor items are previewed prior to the other half of the distractors and the target item. Here, we investigate the nature of this preview by using a top-up procedure, which presents an initial preview followed by a secondary preview after a period of time (the offset period). In Experiment 1, we demonstrate that increasing the time of the offset period decreases search efficiency. If the offset period is increased to $2 \mathrm{sec}$, the previewed items are searched to a greater extent than when the offset period is $450 \mathrm{msec}$. This holds even when the old items remain in the same positions across presentations and when they differ in color from new search stimuli. However, when the offset intervals are reduced, the preview can be discounted from search even when the old items change locations between exposures (Experiment 2) and when they are not distinguished from search displays by their color (Experiment 3). The last result occurs only as long as the preview items can be grouped in terms of form. When the preview stimuli are heterogeneous, they are no longer discounted from search if their locations change across the offset period (Experiment 4). We interpret the data in terms of object-based priming, which enables the repeated form of the old distractors to be filtered more easily from search.
\end{abstract}

In the real world, visual search operates over space, as well as over time, with old information often being less important for survival than new information. Hence, it may have been useful to develop attentional procedures biased toward the new and away from the old stimuli. In order to assess search over time, Watson and Humphreys (1997) developed a preview search procedure in which they divided a standard color-form conjunction display over time, so that the stimuli fell into two presentation intervals: a preview set, involving one of the sets of distractors that make up a conjunction task, and a search set, involving the second set of conjunction distractors and the target. For example, if a conjunction task involved finding a blue $\mathrm{H}$ target among green $\mathrm{H}$ and blue $\mathrm{A}$ distractors, its equivalent preview task would present green Hs initially (in the preview display), followed by the addition of blue As and the blue H (in the search set). The preview and the search displays were separated by $400 \mathrm{msec}$

This work was supported by an ESRC grant to M.A.K. and by an MRC grant to G.W.H. The authors thank Randy Birnkrant for his help with running some of the experiments. We also thank Yuhong Jiang, Mieke Donk, and one anonymous reviewer for their comments. Correspondence concerning this article should be addressed to M. A. Kunar, Visual Attention Laboratory, 64 Sidney Street, Suite 170, Cambridge, MA 02139 (e-mail: kunar@search.bwh.harvard.edu).

Note-This article was accepted by the previous editorial team, when Colin M. MacLeod was Editor. or longer. Watson and Humphreys found that search was much more efficient in the preview condition than in the conjunction condition (the preview benefit). Furthermore, when compared with a single-feature condition, in which only the search set stimuli were presented (e.g., a blue A target among blue $\mathrm{H}$ distractors), the preview condition showed an identical search slope (given as a function of reaction time [RT] over increasing display size). It seemed that when searching for the target item in the preview condition, the participants attended only to the search set and ignored the previewed items.

Watson and Humphreys (1997) also reported that the preview benefit was eliminated if the preview items were offset for a brief period and then reappeared with the onset of the new search displays. This result can be conceptualized in several ways. One is that the preview benefit depends on attention's being captured by the onsets of the new search display (see Donk \& Theeuwes, 2001, for this argument). When the onsets of the new stimuli coincide with those of the re-presented old items, the benefit from onset capture is lost. A second possibility is that the preview benefit depends on temporal segmentation of the old and the new displays (see Jiang, Chun, \& Marks, 2002). When the old and new stimuli appear together, the temporal signals for segmentation are eliminated, so that no preview effect emerges.

Recently, Kunar, Humphreys, and Smith (2003) provided evidence suggesting that onset capture and temporal segmentation were not entirely responsible for the preview 
effect. In their study, they used a top-up preview procedure, which consisted of two parts. First, they presented an initial preview display for $450 \mathrm{msec}$, followed, after an offset period of $250 \mathrm{msec}$, by a secondary re-presentation of the same preview display for $150 \mathrm{msec}$. After the second presentation, the search items were added. This condition was compared with a preview task in which the preview set appeared just $150 \mathrm{msec}$ before the search display. This 150msec separation between the old and the new displays may not be sufficient to generate onset capture (although see Yantis \& Gibson, 1994, who have suggested otherwise) or temporal segmentation and, in fact, showed no benefit in search, when compared with a conjunction condition. Although the temporal intervals of the final displays in the top-up preview and the $150-\mathrm{msec}$ preview were identical, a preview benefit occurred only in the top-up condition. This indicates that the initial presentation of the preview display was crucial to producing efficient search. Kunar, Humphreys, and Smith proposed that the earlier representation "tops up" the effects of the short (150-msec) preview, enabling this preview to be subsequently discounted in search. ${ }^{1}$ The results are consistent with the view originally put forward by Watson and Humphreys (1997) that the benefit is, at least in part, due to inhibition of a representation of the old distractors, which then leads to the old distractors being filtered out from subsequent search. Other evidence consistent with this position has come from studies of dual-task interference on preview search. When participants are engaged in an effortful secondary task during the time when the preview is presented, the preview benefit in search decreases (Humphreys, Watson, \& Jolicœur, 2002; Olivers \& Humphreys, 2002; Watson \& Humphreys, 1997). The secondary task may disrupt any encoding and subsequent filtering of the old items from search.

In the present study, we used the top-up procedure to examine the nature of the representation of the old items that contributes to preview search. Although Kunar, Humphreys, and Smith (2003) demonstrated that it was useful to encode an earlier representation of the old items, they did not examine exactly what form the representation took, or for how long it was available. This was the aim of the present research. Experiment 1 showed that the representation of the preview items decays if the offset period is increased from $450 \mathrm{msec}$ to $2 \mathrm{sec}$. If the offset period is lengthened to $2 \mathrm{sec}$, search efficiency suffers, suggesting that the old items are no longer being ignored in search. In Experiments 2 and 3, we examined the effects of changing the absolute and relative previewed locations during the offset period. This was done with both color-segregated stimuli (Experiment 2) and non-color-segregated stimuli (Experiment 3). In both experiments, the previewed stimuli were homogeneous (i.e., they shared the same form). The data show that a preview benefit can still be found even when the absolute and relative locations of the previewed items change across the offset period for both color-segregated and non-color-segregated stimuli. In Experiment 4, we examined the effects of changing the absolute and relative previewed locations during the offset period, using heterogeneous stimuli. Here, the preview and search stimuli were made up from different letters of the alphabet and so could not be grouped by form. The data show that changing the absolute and relative locations of the previewed items across the offset period disrupted the preview effect. The implications for understanding the representation used in filtering the old items in preview search will be discussed.

To give a brief introduction to the methods we used, in the conjunction condition and each preview condition in each experiment, there were 4,8 , or 16 items in total in the search displays. The conjunction condition provided a measure of search efficiency if all the items compete for selection in the final displays of the preview conditions. If the old items cannot be ignored, the slope of the functions for the preview conditions should match that found in the conjunction condition. If, however, the old items can be ignored (at least to some extent), the slope for the preview condition should show greater efficiency than does that for the conjunction condition. The single-feature condition consisted of just the new stimuli used in preview search (i.e., half the display size, corresponding to one set of distractors, of that used in the conjunction condition), in line with Watson and Humphreys's (1997) methodology. If only the new items are searched in preview displays, the slope of the search function in the preview condition should match that found in the single-feature condition. On the other hand, if the old items are being searched (at least to some degree), the slope of the preview condition should be greater than that for the single-feature condition. Therefore, when the data are analyzed, it is important to compare the top-up conditions in question with both the single-feature and the conjunction conditions, to see whether the old items are being searched. It can also be the case that the efficiency shown by the preview slope falls in between that shown by the single-feature and the conjunction conditions (and thus should be reliably different from both). This would suggest that although the old items are not fully discounted from search (hence, the preview slope shows less efficiency than does that for the single feature), neither are they being attended as much as the equivalent distractors in the conjunction condition. The latter comparison is important. Preview search investigates whether there is any benefit to search when distractors are presented before the search set. If the slopes of the search functions show more efficiency for the preview condition than for the conjunction condition (even if they show less efficiency than do those in the single-feature condition), the data indicate that the old items are being discounted from search to some degree. The critical comparisons, then, concern the interactions between the variables of condition (preview vs. single feature or preview vs. conjunction) and display size. A significant condition $\times$ display size interaction for the comparison between the preview and the conjunction conditions is taken to imply that the preview items are not being searched as fully as they would have been had they been presented at the same time as the remaining search set. Likewise, if the condition $\times$ display size interaction (and the slopes) in each preview 
condition is different from that in the single-feature condition, this would imply that the preview items are being searched (at least to some extent). Since it is the pattern of data across the display size that gives information as to whether the preview items are being searched, the results are not broken down into comparisons between the individual means at each display size.

\section{EXPERIMENT 1}

Experiment 1 comprised two subexperiments. In both subexperiments, an initial preview appeared for $450 \mathrm{msec}$, and a later preview appeared for just $150 \mathrm{msec}$, prior to the search display. Kunar, Humphreys, and Smith (2003) showed that this brief 150 -msec preview did not generate a preview benefit in search in its own right (see also Humphreys et al., 2004; Watson \& Humphreys, 1997). In Experiment 1A, the initial preview offset for $450 \mathrm{msec}$ before the subsequent brief preview. In Experiment 1B, the offset period was $2 \mathrm{sec}$. We asked whether any representation of the old items would be sustained across these periods, to generate a preview benefit.

\section{Method}

Participants. Twelve participants ( 2 of them male and 10 female) took part in Experiment 1A and a separate 12 ( 1 of them male and 11 female) took part in Experiment 1B. All the participants took part for the attainment of course credits. The age range for the participants in Experiment $1 \mathrm{~A}$ was $18-23$ years (mean age, 20 years), whereas in Experiment 1B, it was $18-25$ years (mean age, 20.5 years). All the participants were taken from a population of undergraduates at the University of Birmingham and had normal or corrected-to-normal eyesight.

Stimuli. All the stimuli were produced by a Turbo Pascal computer program and run on a Pentium computer with a VGA graphics card. The letters subtending a visual angle of $0.4^{\circ} \times 0.8^{\circ}$ at an observation distance of $60 \mathrm{~cm}$ were randomly positioned within a $10 \times$ 10 matrix of visual angle $8.5^{\circ} \times 9.9^{\circ}$ (with the constraint that no two letters could occupy the same location at the same time).

The search task involved finding a blue H (CIE $x, y$ chromaticity coordinates of $.210, .298 ; 35 \mathrm{~cd} / \mathrm{m}^{2}$ ) among distractor items of green Hs (CIE $x, y$ chromaticity coordinates of .238, .439; $47 \mathrm{~cd} /$ $\mathrm{m}^{2}$ ) and blue As (CIE $x, y$ chromaticity coordinates of $.210, .298$; $35 \mathrm{~cd} / \mathrm{m}^{2}$ ). On each trial, the participants had to decide whether the bar of the blue $\mathrm{H}$ was higher or lower than the midpoint of the $y$-axis for the shape. The surrounding green $\mathrm{H}$ distractors also randomly had bars in a position above the vertical midpoint or below it, in order to preserve conjunction conditions. Therefore, the shapes of the distractor Hs were similar to that of the target $\mathrm{H}$ across trials. The target was present on every trial. Although this is a small change relative to the "classic" target present-absent tasks used by Watson and Humphreys (1997), several other studies have now employed similar procedures and have reported search functions equivalent to those used in target present-absent tasks (e.g., Kunar, Humphreys, \& Smith, 2003; Kunar, Humphreys, Smith, \& Watson, 2003; Olivers \& Humphreys, 2002).

Design and Procedure. In Experiment 1A, each participant was tested in three conditions: (1) a single-feature condition (blue As and a blue H), (2) a conjunction condition (blue and green letters presented simultaneously), and (3) a top-up preview condition with a 450-msec offset between previews (green letters appear for $450 \mathrm{msec}$, offset for $450 \mathrm{msec}$, before reappearing again $150 \mathrm{msec}$ before the blue items appear). Each search condition was presented in a separate block. Experiment 1B was identical to this, except that in the top-up preview condition, the offset period between previews was increased to $2,000 \mathrm{msec}$. Each of the experimental blocks contained 60 trials ( 20 per display size). The order of blocks was randomized, and the participants were given practice before each condition. Each experiment lasted approximately $30 \mathrm{~min}$ in total.

In each condition, a fixation dot appeared on the screen for $1,000 \mathrm{msec}$, followed by either the preview or the full search display (in the single-feature and conjunction conditions). The participants were asked to keep their eyes on the fixation dot until the second set of stimuli were presented and then to respond to the blue $\mathrm{H}$ by pressing either an " $m$ " or a " $z$ " for a high or a low bar. Response keys were counterbalanced across participants. Example displays for each condition can be seen in Figure 1.

\section{Results and Discussion}

RTs more than three standard deviations away from each condition mean or less than $200 \mathrm{msec}$ were eliminated. This procedure removed $1.1 \%$ of the data from Experiment $1 \mathrm{~A}$ and $0.9 \%$ of the data from Experiment $1 \mathrm{~B}$ (all outlier data were labeled as errors). One participant was removed from Experiment 1B due to high error rates (above $25 \%$ in some cases). Figure 2 shows the mean correct RTs as a function of display size for Experiments 1A and 1B. The error rates are given in Table 1, and Table 2 shows the search slopes. Error rates were generally low, and since they showed little evidence of a speed-accuracy trade-off (i.e., in general, the participants were more accurate in conditions in which they showed shorter RTs), they were not analyzed further. Mean correct RTs were entered into two-way ANOVAs with condition and display size as variables.

Preview compared with single-feature condition, Experiment 1A. Experiment 1A replicated the results in Kunar, Humphreys, and Smith (2003) on top-up search. When the 450-msec offset preview was compared with the single-feature task, there were reliable main effects of condition $\left[F(1,11)=6.61, M S_{\mathrm{e}}=75,791, p<.05\right]$ and of display size $\left[F(2,22)=41.59, M S_{\mathrm{e}}=215,016, p<.01\right]$. The condition $\times$ display size interaction also reached significance $\left[F(2,22)=3.72, M S_{\mathrm{e}}=8,599, p<.05\right]$. There was a greater increase in RTs with increases in display size for the top-up preview than in the single-feature condition. Likewise, a separate ANOVA on search slopes showed search in the single-feature condition to be more efficient than that in the top-up condition, although this effect was only marginal $\left[F(1,11)=4.34, M S_{\mathrm{e}}=187, p=.06\right]$. The data suggest that the old items may have been searched, to some degree, since the search slopes in this preview condition showed greater efficiency than did those in the single-feature condition.

Preview compared with conjunction condition, Experiment 1A. Although this is of note, it is more important that there was a benefit in search when the 450msec offset preview condition was compared with the conjunction condition. Here, there were reliable main effects of condition $\left[F(1,11)=13.05, M S_{\mathrm{e}}=72,416, p<.01\right]$ and of display size $\left[F(2,22)=122.59, M S_{\mathrm{e}}=508,698\right.$, $p<.01]$. The condition $\times$ display size interaction also reached significance $\left[F(2,22)=4.44, M S_{\mathrm{e}}=29,120, p<\right.$ $.05]$. There was a greater increase in RTs with increases 


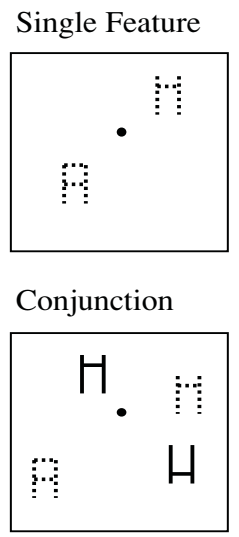

450- or 2,000-msec Offset Top-up Preview

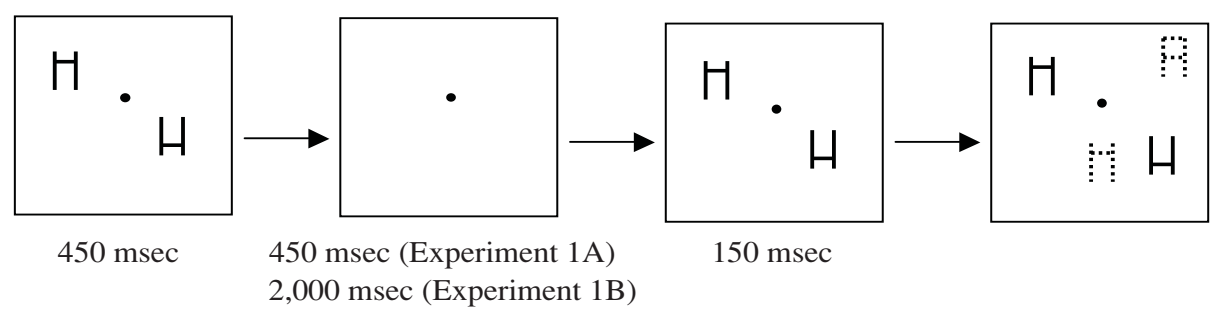

Figure 1. Example displays for each condition in Experiments 1A and 1B. The variability in the locations of the items is not accurately portrayed. There were 100 possible item locations in each display.

in display size in the conjunction condition than in the top-up preview condition, and search slopes in the top-up condition showed greater efficiency than did those for the conjunction task $\left[F(1,11)=6.07, M S_{\mathrm{e}}=766, p<.05\right]$. Both the interactions and the slope analysis show that a reliable preview benefit emerged in terms of search efficiency (relative to the conjunction condition), even though the preview had offset for a period of $450 \mathrm{msec}$ prior to the subsequent $150-\mathrm{msec}$ preview. The old items were not being searched fully in the top-up preview, in comparison with when they were presented alongside the new items in the conjunction condition. This difference seemed to occur primarily at set size 16 , where there was a notable difference between the conjunction and the preview conditions (although RTs at set sizes 4 and 8 were numerically shorter in the preview condition, there was some overlap with the conjunction RTs).

Preview compared with single-feature condition, Experiment 1B. In contrast, the data in Experiment 1B show that no preview effect occurred when the old items offset for 2,000 msec. When the single-feature and the 2,000-msec offset preview conditions were compared, there were reliable main effects of condition $[F(1,10)=$ $\left.22.88, M S_{\mathrm{e}}=344,226, p<.01\right]$ and of display size $\left[F(2,20)=90.26, M S_{\mathrm{e}}=315,491, p<.01\right]$. The condition $\times$ display size interaction also reached significance $\left[F(2,20)=4.45, M S_{\mathrm{e}}=12,116, p<.05\right]$. There was a greater increase in RTs with increases in display size for the top-up preview than in the single-feature condition. Search slopes in the single-feature condition showed greater efficiency than did those in the top-up condition $\left[F(1,10)=6.01, M S_{\mathrm{e}}=324, p<.05\right]$.

Preview compared with conjunction condition, Experiment 1B. However, there was no reliable effect of condition when the 2,000-msec offset preview condition was compared with the conjunction condition. There was a main effect of display size $\left[F(2,20)=63.19, M S_{\mathrm{e}}=572\right.$, $631, p<.01]$, but the condition $\times$ display size interaction did not reach significance. Neither was there a reliable difference between the search slopes. The results show that when the offset period was increased to $2,000 \mathrm{msec}$, the old stimuli were being fully searched among the new. Taking the results together, it seems that the representation of the original preview decays with time, so that increasing the offset period to $2 \mathrm{sec}$ causes a decrease in search efficiency. If the offset period is extended to this time, the representation of the original preview is less available to support the filtering of the old items from subsequent search.

Kunar, Humphreys, and Smith (2003) demonstrated that the $150-\mathrm{msec}$ preview alone was not sufficient to generate a benefit for search, and this is also supported by the data from Experiment 1B. In Experiment 1B, there was a $150-\mathrm{msec}$ preview immediately prior to the search display, but no search benefit was evident. The data from Experiment $1 \mathrm{~A}$ indicate that a representation of the initial preview survived a 450-msec offset, in order to "top up" any effect of the subsequent short preview. Performance with a 450-msec offset of the preview was not quite as efficient as that in the single-feature condition (although this 

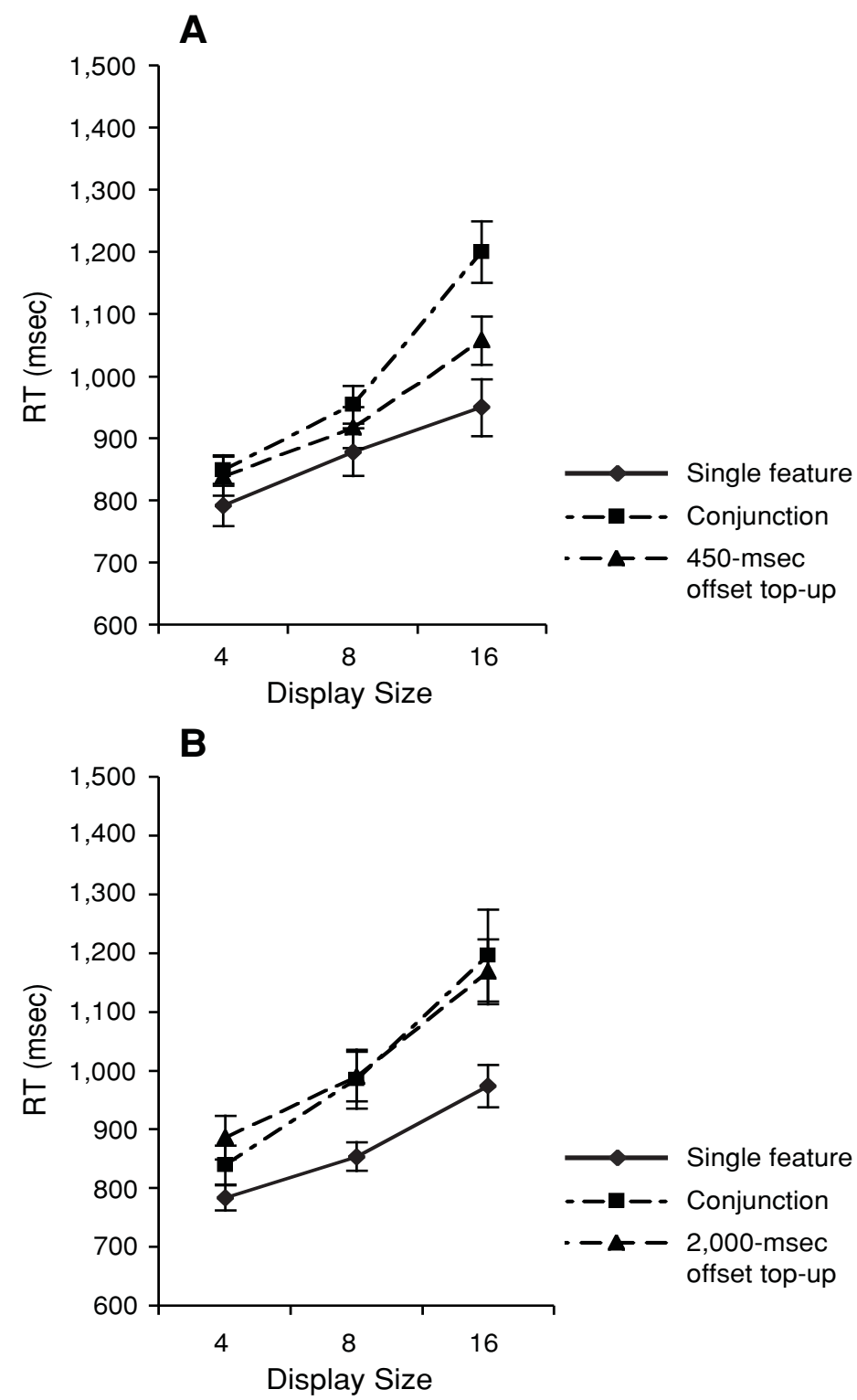

Figure 2. (A) Mean correct reaction times (RTs, in milliseconds) for each condition in Experiment 1A. (B) Mean correct RTs for each condition in Experiment 1B. Note that the single-feature condition had half as many items as did the conjunction condition and the final display in the preview condition.

difference was only marginal when the search slopes were compared), but in the other experiments reported here, we found a robust preview advantage under similar (and even more extended) temporal conditions, with performance sometimes equivalent to that in the single-feature condition. Hence, although there may be some small effect of old distractors, the data demonstrate that these items have much less impact than in the conjunction condition, when all the items appear simultaneously.

These data on top-up effects in preview search remain difficult for theories assuming that onset capture and temporal segmentation of the old and new displays alone are crucial for performance. As in Kunar, Humphreys, and
Smith (2003), the temporal parameters of the preview and the search displays were kept constant, yet the presentation of the earlier previews still enabled the old items to be discounted from search (providing that the offset period was not extended to $2 \mathrm{sec}$ ). Note also that the offset intervals used here were easily long enough to ensure clear perceptual segregation of the first from the second presentation of the preview (indeed, see Watson \& Humphreys, 1997, for evidence of segmentation with just a 250-msec offset). The onset and temporal segmentation accounts need to be extended to account for these data.

Having shown that increasing the offset period to $2 \mathrm{sec}$ decreases search efficiency, in Experiments 2 and 3 we 
Table 1

Percentages of Errors in the Different Search Conditions Across Experiments 1-4 for Each Display Size

\begin{tabular}{|c|c|c|c|c|c|c|}
\hline \multirow[b]{2}{*}{ Condition } & \multicolumn{2}{|c|}{$\begin{array}{l}\text { Display } \\
\text { Size } 4\end{array}$} & \multicolumn{2}{|c|}{$\begin{array}{c}\text { Display } \\
\text { Size } 8\end{array}$} & \multicolumn{2}{|c|}{$\begin{array}{l}\text { Display } \\
\text { Size } 16\end{array}$} \\
\hline & $M$ & $S D$ & $M$ & $S D$ & $M$ & $S D$ \\
\hline \multicolumn{7}{|l|}{ Experiment $1 \mathrm{~A}$} \\
\hline Single feature & 2.5 & 2.6 & 5.4 & 4.0 & 4.6 & 3.3 \\
\hline Conjunction & 2.5 & 2.6 & 2.1 & 3.3 & 7.9 & 4.5 \\
\hline 450-msec offset top-up & 4.2 & 6.0 & 2.9 & 3.3 & 8.8 & 5.3 \\
\hline \multicolumn{7}{|l|}{ Experiment 1B } \\
\hline Single feature & 2.7 & 3.4 & 1.8 & 3.4 & 4.5 & 4.7 \\
\hline Conjunction & 1.4 & 2.3 & 2.7 & 2.6 & 7.3 & 6.5 \\
\hline 2,000 -msec offset top-up & 1.8 & 2.5 & 2.3 & 3.4 & 7.7 & 6.5 \\
\hline \multicolumn{7}{|l|}{ Experiment 2} \\
\hline Single feature & 2.7 & 4.2 & 3.3 & 5.6 & 5.7 & 3.7 \\
\hline Conjunction & 2.7 & 3.7 & 3.0 & 3.2 & 6.3 & 4.4 \\
\hline Location change and $250-\mathrm{msec}$ offset top-up & 3.3 & 4.5 & 2.7 & 3.2 & 9.0 & 5.5 \\
\hline Location change and $450-\mathrm{msec}$ offset top-up & 5.3 & 4.0 & 3.0 & 3.2 & 6.0 & 3.9 \\
\hline Location change and 1,000 -msec offset top-up & 2.7 & 4.2 & 2.0 & 4.6 & 7.7 & 5.6 \\
\hline \multicolumn{7}{|l|}{ Experiment 3} \\
\hline Single feature & 3.4 & 4.4 & 0.9 & 2.0 & 4.1 & 3.8 \\
\hline Conjunction & 1.9 & 3.1 & 1.6 & 2.4 & 8.1 & 4.0 \\
\hline 1,000 -msec offset top-up & 1.9 & 4.0 & 1.9 & 2.5 & 7.8 & 3.6 \\
\hline Location change and 1,000 -msec offset top-up & 1.6 & 3.0 & 3.1 & 4.0 & 7.8 & 4.1 \\
\hline \multicolumn{7}{|l|}{ Experiment 4} \\
\hline Conjunction & 3.6 & 3.1 & 2.9 & 4.3 & 1.8 & 3.2 \\
\hline Standard top-up preview & 3.6 & 4.6 & 3.9 & 4.5 & 2.9 & 3.8 \\
\hline Location change top-up preview & 2.9 & 4.7 & 2.1 & 2.6 & 3.9 & 6.3 \\
\hline 150-msec preview & 5.7 & 6.5 & 5.7 & 4.7 & 3.2 & 3.7 \\
\hline
\end{tabular}

Note-The single-feature condition had half as many items as did the conjunction condition and the final display in the preview condition.

proceeded to examine the nature of the representation of the old stimuli that gives rise to the top-up effect. In Experiment 2, we used displays similar to those in Experiment 1 but changed the locations of the stimuli in the preview, between the initial and the subsequent displays. If the locations of individual items and the whole configuration are represented, changing their properties during the offset should disrupt the top-up effect. If, however, other factors, such as color and/or object identity, are important, a preview effect should still occur.

\section{EXPERIMENT 2}

In Experiment 2, there were three offset intervals between the initial presentation of the preview $(450 \mathrm{msec})$ and its subsequent short exposure $(150 \mathrm{msec})$ prior to the search display: 250-, 450-, and 1,000-msec offsets. The experiment tested whether the representation of the initial preview would last for at least $1 \mathrm{sec}$, if not for $2 \mathrm{sec}$, where there was a decrease in search efficiency (Experiment 1B). In addition, the locations of the old items always changed across the offsets. ${ }^{2}$ Would the top-up effect be present despite such changes?

\section{Method}

Participants. Fifteen participants ( 1 of them male and 14 female) took part for the attainment of course credits. Their ages ranged from 18 to 26 years (mean age, 20.3 years), and they were all taken from a population of undergraduates at the University of Birmingham. All the participants had normal or corrected-to-normal eyesight.

Stimuli. The stimuli were the same as those used in Experiment 1.

Design and Procedure. Each participant was tested in five conditions: a single-feature condition (blue As and a blue $\mathrm{H}$ ), a conjunction condition (blue and green letters presented simultaneously), and three top-up preview conditions with offsets of (1) $250 \mathrm{msec}$, (2) $450 \mathrm{msec}$, and (3) 1,000 msec. In these preview conditions, there was an initial preview of $450 \mathrm{msec}$ prior to the offset and a subsequent exposure of $150 \mathrm{msec}$ before the search displays (blue letters). Also, the old items were assigned to new, random locations during the offset, with the constraint that no preview item could move to a previously occupied location. Since each item moved independently, the initial configuration of the preview was disrupted. Each search condition was presented in a separate block. Each of the experimental blocks contained 60 trials ( 20 per display size). The order of the blocks was randomized, and the participants were given a practice session before each condition. The experiment lasted approximately $30 \mathrm{~min}$ in total.

In each condition, a fixation dot appeared on the screen for $1,000 \mathrm{msec}$, followed by either the preview or the full search display (in the single-feature and conjunction conditions). The participants were asked to keep their eyes on the fixation dot until the second set of stimuli was presented and then to respond to the blue $\mathrm{H}$ by pressing either an "m" or a " $z$ " for a high or a low bar. Response keys were counterbalanced across participants. Example displays for the top-up preview conditions can be seen in Figure 3.

\section{Results and Discussion}

Figure 4 shows the mean correct RTs as a function of display size for Experiment 2. The error rates are given in 
Table 2

Search Slope Statistics (Milliseconds/Item) for the Different Search Conditions Across Experiments 1-4

\begin{tabular}{lrr}
\hline \multicolumn{1}{c}{ Condition } & $M$ & $S D$ \\
\hline Experiment 1A & 13 & 6 \\
Single feature & 30 & 9 \\
Conjunction & 18 & 11 \\
450-msec offset top-up & & \\
Experiment 1B & 16 & 7 \\
Single feature & 29 & 16 \\
Conjunction & 23 & 9 \\
2,000-msec offset top-up & & \\
Experiment 2 & 16 & 10 \\
Single feature & 32 & 15 \\
Conjunction & 21 & 12 \\
Location change and 250-msec offset top-up & 22 & 11 \\
Location change and 450-msec offset top-up & 17 & 11 \\
Location change and 1,000-msec offset top-up & & \\
Experiment 3 & 24 & 9 \\
Single feature & 73 & 48 \\
Conjunction & 40 & 23 \\
1,000-msec offset top-up & 51 & 22 \\
Location change and 1,000-msec offset top-up & & \\
Experiment 4 & 46 & 12 \\
Conjunction & 35 & 16 \\
Standard top-up preview & 49 & 19 \\
Location change top-up preview & 51 & 17 \\
150-msec preview & & \\
\hline
\end{tabular}

Note-The single-feature condition had half as many items as did the conjunction condition and the final display in the preview condition.

Table 1, and Table 2 shows the search slopes. Error rates were generally low, and since they showed no sign of a speed-accuracy trade-off, they were not examined further. RTs more than three standard deviations away from each condition mean or less than $200 \mathrm{msec}$ were eliminated. This procedure removed $0.6 \%$ of the data.

Preview compared with single-feature condition. Examining the RT data for the offset previews, relative to the single-feature condition, we see that with the 250msec offset preview, there were reliable main effects of condition $\left[F(1,14)=22.50, M S_{\mathrm{e}}=126,018, p<.01\right]$ and of display size $\left[F(2,28)=48.20, M S_{\mathrm{e}}=377,323, p<\right.$ $.01]$. However, the condition $\times$ display size interaction was not reliable. Neither was there a difference in search slope. The 450-msec offset preview and single-feature comparison showed reliable main effects of condition $\left[F(1,14)=10.58, M S_{\mathrm{e}}=177,119, p<.01\right]$ and of display size $\left[F(2,28)=49.57, M S_{\mathrm{e}}=412,648, p<.01\right]$. The condition $\times$ display size interaction reached significance $\left[F(2,28)=5.69, M S_{\mathrm{e}}=11,025, p<.01\right]$. There was a greater increase in RTs with increases in display size in the top-up preview condition than in the single-feature condition, and search slopes showed greater efficiency in the single-feature condition than in the top-up condition $\left[F(1,14)=9.38, M S_{\mathrm{e}}=291, p<.01\right]$. With the $1,000-$ msec offset top-up and single-feature comparison, there were reliable main effects of condition $[F(1,14)=8.01$, $\left.M S_{\mathrm{e}}=106,911, p<.05\right]$ and of display size $[F(2,28)=$ $\left.60.13, M S_{\mathrm{e}}=317,069, p<.01\right]$. However, the condition $\times$ display size interaction was not reliable. Neither was there a difference in search slope. Although there were general trends for search in the preview conditions to be slower than that in the single-feature conditions, this was not reliable for two of the three cases (250- and 1,000msec previews). The data for the $450-\mathrm{msec}$ preview were slightly puzzling. Here, the search slopes did not show

Single Feature

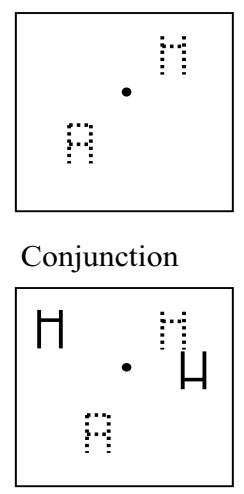

Location Change and 250-, 450-, or 1,000-msec Top-up Preview

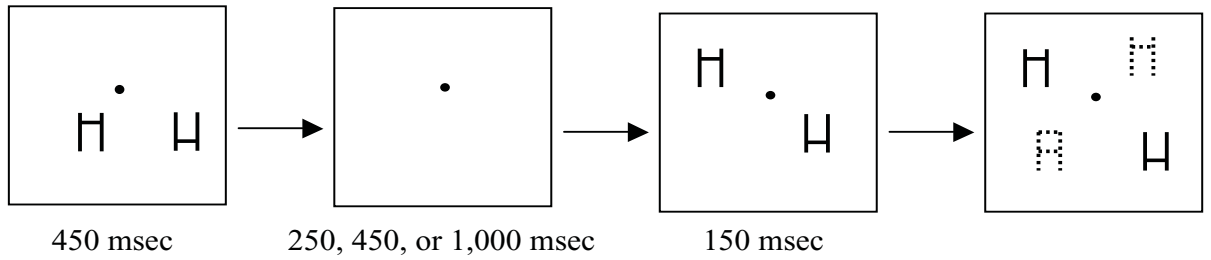

Figure 3. Example displays in Experiment 2. The variability in the locations of the items is not accurately portrayed. There were 100 possible item locations in each display. 


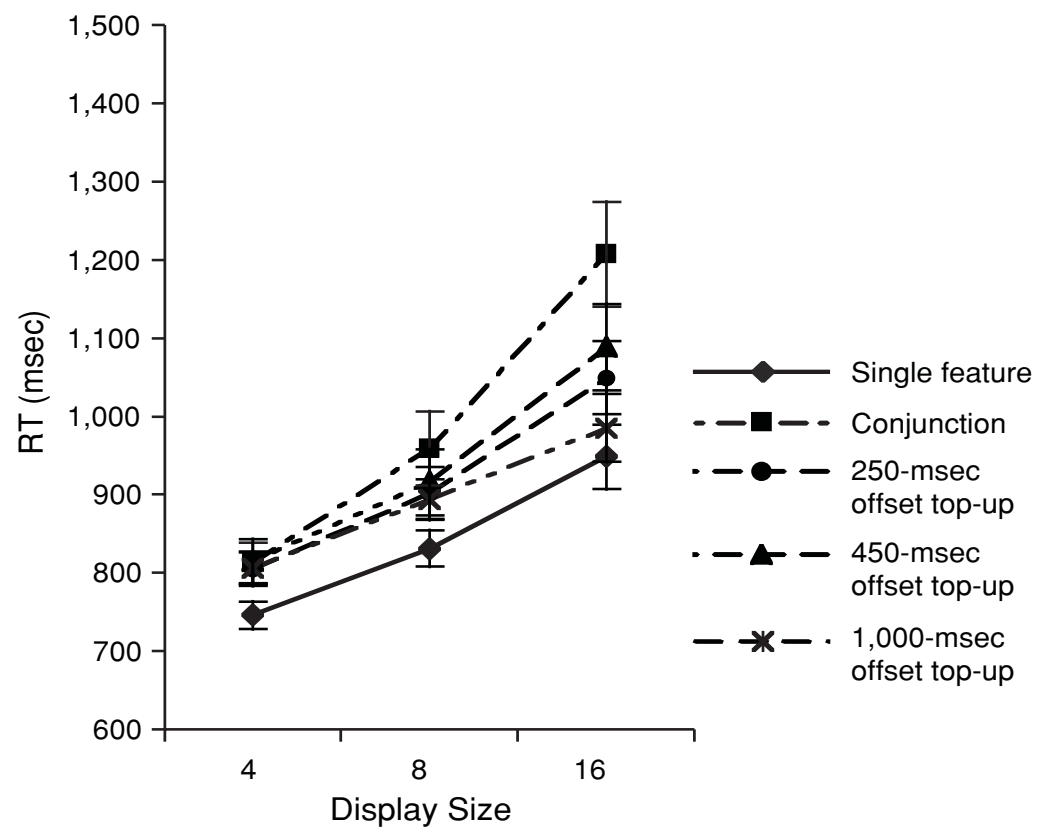

Figure 4. Mean correct reaction times (RTs, in milliseconds) for each condition in Experiment 2. Note that the single-feature condition had half as many items as did the conjunction condition and the final display in the preview condition.

search to be as efficient as in the single-feature condition, suggesting that the old items were being searched to some extent. It is not immediately obvious why this might be the case-especially, since the old items in the 250- and 1,000 -msec previews were completely discounted from search.

Preview compared with conjunction condition. However, more important, all three top-up conditions showed reliable preview benefits when compared with the conjunction condition. With the 250-msec offset top-up, there were reliable main effects of condition $[F(1,14)=$ $\left.11.36, M S_{\mathrm{e}}=123,302, p<.01\right]$ and of display size $\left[F(2,28)=57.12, M S_{\mathrm{e}}=771,073, p<.01\right]$. The condition $\times$ display size interaction also reached significance $\left[F(2,28)=8.73, M S_{\mathrm{e}}=35,826, p<.01\right]$. There was a greater increase in RTs with increases in display size in the conjunction condition than in the top-up preview, and search slopes showed greater efficiency in the top-up condition than in the conjunction condition $[F(1,14)=$ $\left.12.48, M S_{\mathrm{e}}=959, p<.01\right]$. With the $450-\mathrm{msec}$ offset top-up, there were reliable main effects of condition $\left[F(1,14)=17.16, M S_{\mathrm{e}}=81,384, p<.01\right]$ and of display size $\left[F(2,28)=63.52, M S_{\mathrm{e}}=821,518, p<.01\right]$. The condition $\times$ display size interaction also reached significance $\left[F(2,28)=5.35, M S_{\mathrm{e}}=25,879, p<.05\right]$. There was a greater increase in RTs with increases in display size in the conjunction condition than in the top-up preview condition, and search slopes showed greater efficiency in the top-up condition than in the conjunction condition $\left[F(1,14)=8.41, M S_{\mathrm{e}}=693, p<.01\right]$. Comparing the 1,000 -msec offset preview with the conjunction, there was no reliable main effect of condition. However, there was a main effect of display size $\left[F(2,28)=76.08, M S_{\mathrm{e}}=682,637\right.$, $p<.01]$, and the condition $\times$ display size interaction also reached significance $\left[F(2,28)=7.42, M S_{\mathrm{e}}=58,698, p<\right.$ $.01]$. There was a greater increase in RTs with increases in display size in the conjunction condition than in the top-up preview condition, and search slopes showed greater efficiency in the top-up condition than in the conjunction condition $\left[F(1,14)=8.86, M S_{\mathrm{e}}=1,566, p<.01\right]$. In all three preview conditions, the old items were not being searched as fully as they were when presented simultaneously with the search set (i.e., in the conjunction condition).

The data show that the representation mediating the top-up effect appeared to last at least $1 \mathrm{sec}$, even if any effects were negligible after a 2 -sec offset period (Experiment 1B). In addition, performance in all the top-up conditions here survived changes in the positions of the old items, relative to the conjunction condition. The representation of the old items that is generated and carried across to the subsequent preview either is not sensitive to the locations of the old items or enables the subsequent preview display to be more rapidly encoded and, thus, filtered than would otherwise be the case, even when the locations of the old items have to be recomputed.

One possible reason for the robustness of the results with respect to the position changes is that the old items always differed in color, relative to the new stimuli. A process of filtering by color (in addition to the temporal differences between the old and the new displays) would generate efficient search and also minimal effects of location change if just the color of the initial preview were maintained across the offset interval. Several studies have demonstrated inhibitory filtering by color under preview 
conditions (Braithwaite \& Humphreys, 2003; Olivers \& Humphreys, 2002). To test whether this was important to the present results, we eliminated the color differences between the old and the new displays in Experiment 3 and examined whether the top-up effect would be sensitive to changing the locations of the old items across preview offset.

\section{EXPERIMENT 3}

\section{Method}

Participants. Sixteen participants ( 4 of them male and 12 female) took part for the attainment of course credits. Their ages ranged from 18 to 27 years (mean age, 20.9 years), and they were all taken from a population of undergraduates at the University of Birmingham. All the participants had normal or corrected-to-normal eyesight.

Stimuli. The stimuli were taken from Olivers, Watson, and Humphreys (1999) and consisted of capital Ts presented in different orientations. ${ }^{3}$ The distractor items were either upright Ts or Ts rotated counterclockwise $90^{\circ}$ against the vertical. The letters, subtending a visual angle of $0.8^{\circ} \times 0.8^{\circ}$ at an observation distance of $60 \mathrm{~cm}$, were randomly positioned within a stimulus field of visual angle $11.8^{\circ} \times$ $11.8^{\circ}$. The target item was always an upside-down T. On each trial, the participants had to respond to a small gap presented on either the left or the right of the horizontal bar of the upside-down T. The participants pressed " $z$ " with their left hand if the gap fell to the left of the vertical line (bisecting the horizontal line to make up the $T$ shape) and " $\mathrm{m}$ " with their right hand if the gap fell to the right of the vertical line. The surrounding distractor $\mathrm{T}$ items also had gaps positioned on the right or the left of the bisected "horizontal" line to preserve conjunction conditions. (Note that the "horizontal" line making up the T was actually in a vertical position when the distractor items were rotated $90^{\circ}$.) The target was present on every trial.

There were four search conditions: (1) a single-feature condition, ${ }^{4}$ (2) a conjunction condition, (3) a 1,000-msec offset preview condition with no location change, and (4) a 1,000-msec offset condition with a location change for the old letters across the offset interval. The conjunction and preview conditions comprised 4,8 , or 16 items in total, whereas the single feature condition comprised 2,4 , or 8 items (see Experiment 1 for details). In the preview conditions, one set of distractors (containing $n / 2$ upright Ts if the total display size equaled $n$ ) was presented ahead of the second set $\left(90^{\circ}\right.$ rotated Ts and an inverted T). Each search condition was presented in a separate block. Each of the experimental blocks contained 60 trials ( 20 per display size), and the order of the blocks was randomized across participants.

Design and Procedure. In the conjunction search, a fixation dot was presented for 1,000 msec before the target item, which appeared simultaneously alongside upright $\mathrm{Ts}$ and rotated $\mathrm{T}$ distractors (rotated $90^{\circ}$ counterclockwise). The participants were asked to search and respond to the position of the gap on the inverted T. The single-feature condition was similar, except that the target item appeared only with half of the distractor items (the rotated Ts). In the 1,000-msec offset preview, a fixation dot appeared on the screen for $1,000 \mathrm{msec}$, followed by upright Ts. They remained on the screen for $450 \mathrm{msec}$ before offsetting for $1,000 \mathrm{msec}$ and then reappearing in their initial locations for $150 \mathrm{msec}$ before the new items appeared (Ts that had been rotated $90^{\circ}$ and the upside-down $\mathrm{T}$ target item). ${ }^{5}$ In the 1,000 -msec offset and location change preview, a fixation dot again appeared for $1,000 \mathrm{msec}$, followed by upright Ts. The upright Ts were presented for $450 \mathrm{msec}$ before disappearing for $1,000 \mathrm{msec}$ and then reappearing in a previously unoccupied location for $150 \mathrm{msec}$ before the onset of the new items (rotated Ts and the target, an upside-down T). This change in the location of the old items across the offset period destroyed the original configural cues in the preview display. The participants were instructed to keep their eyes on the central fixation point until the second set of items appeared. Examples of each display can be seen in Figure 5.

\section{Results and Discussion}

Figure 6 shows the mean correct RTs as a function of display size for Experiment 3. The error rates are given in Table 1, and Table 2 shows the search slopes. Error rates were generally low, and since they showed no sign of a speed-accuracy trade-off, they were not examined further. RTs more than three standard deviations away from each condition mean or less than $200 \mathrm{msec}$ were eliminated. This procedure removed $0.6 \%$ of the data.

Preview compared with single-feature condition. When the RT data for the preview conditions were examined in relation to those for the single-feature condition, the results showed that with the 1,000-msec offset preview, there were reliable main effects of condition $\left[F(1,15)=18.12, M S_{\mathrm{e}}=614,422, p<.01\right]$ and of display size $\left[F(2,30)=74.16, M S_{\mathrm{e}}=1,268,027, p<.01\right]$. The condition $\times$ display size interaction also reached significance $\left[F(2,30)=8.68, M S_{\mathrm{e}}=80,310, p<.01\right]$. There was a greater increase in RTs with increases in display size in the top-up preview condition than in the single-feature condition, and search slopes showed reliably greater efficiency in the single-feature condition than in the top-up condition $\left[F(1,15)=10.92, M S_{\mathrm{e}}=2,150, p<.01\right]$. With the 1,000-msec offset and location change preview, there were reliable main effects of condition $[F(1,15)=31.99$, $\left.M S_{\mathrm{e}}=1,311,084, p<.01\right]$ and of display size $[F(2,30)=$ $\left.106.32, M S_{\mathrm{e}}=1,718,864, p<.01\right]$. The condition $\times$ display size interaction also reached significance $[F(2,30)=$ $\left.27.67, M S_{\mathrm{e}}=221,765, p<.01\right]$. There was a greater increase in RTs with increases in display size in the top-up preview condition than in the single-feature condition, and search slopes showed greater efficiency in the singlefeature condition than in the top-up condition $[F(1,15)=$ 37.55, $\left.M S_{\mathrm{e}}=5,937, p<.01\right]$.

Preview compared with conjunction condition. We subsequently compared each preview condition with the conjunction condition. With the 1,000-msec offset preview, there were reliable main effects of condition $[F(1,15)=$ $\left.14.83, M S_{\mathrm{e}}=2,582,132, p<.01\right]$ and of display size $\left[F(2,30)=60.89, M S_{\mathrm{e}}=3,869,278, p<.01\right]$. The condition $\times$ display size interaction also reached significance $\left[F(2,30)=6.30, M S_{\mathrm{e}}=334,896, p<.01\right]$. There was a greater increase in RTs with increases in display size in the conjunction condition than in the top-up preview condition, and search slopes showed greater efficiency in the top-up condition than in the conjunction condition $\left[F(1,15)=6.74, M S_{\mathrm{e}}=8,673, p<.05\right]$. Similarly, with the 1,000-msec offset and location change preview, there were reliable main effects of condition $[F(1,15)=18.35$, $\left.M S_{\mathrm{e}}=1,551,835, p<.01\right]$ and of display size $[F(2,30)=$ 64.38, $\left.M S_{\mathrm{e}}=4,640,963, p<.01\right]$. The condition $\times$ display size interaction also reached significance $[F(2,30)=$ $\left.3.67, M S_{\mathrm{e}}=155,504, p<.05\right]$. There was a greater increase in RTs with increases in display size in the conjunction condition than in the top-up preview condition, and search slopes showed marginally greater efficiency 
Single Feature

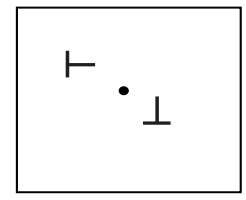

Conjunction

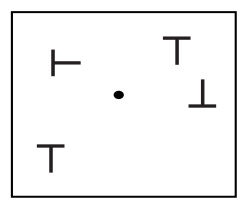

1,000-msec Offset Top-up Preview

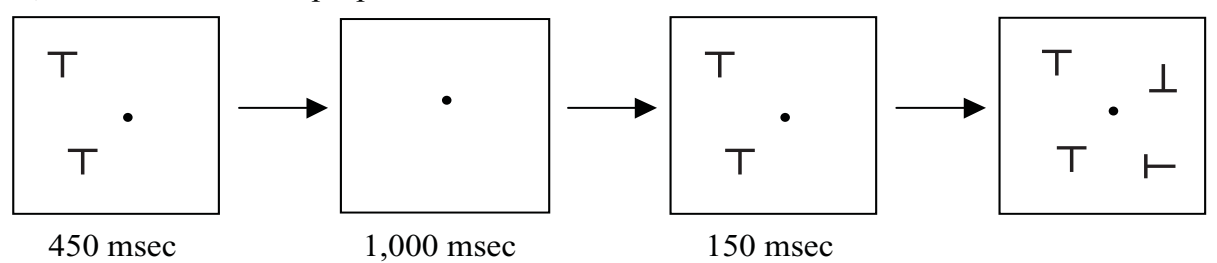

Location change and 1,000-msec Top-up Preview

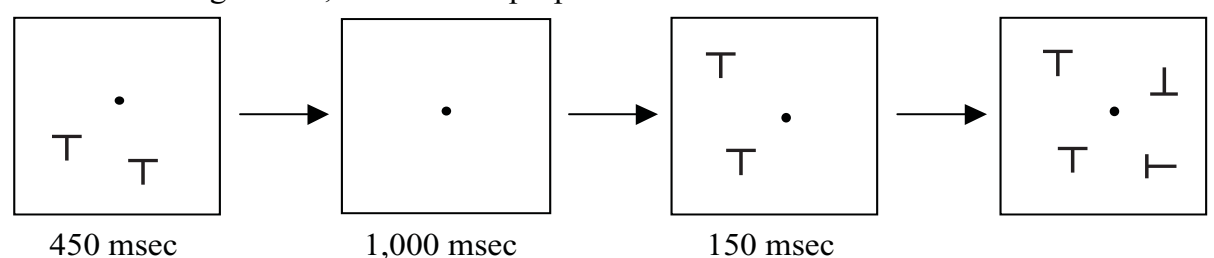

Figure 5. Example displays in Experiment 3. Note that the "horizontal" line of the $T$ had a small space either to the left or the right of the "vertical" line in the experiment proper. The variability in locations of items is not accurately portrayed. There were 100 possible item locations in each display.

in the top-up condition than in the conjunction condition $\left[F(1,15)=4.10, M S_{\mathrm{e}}=3,900, p=.06\right]$.

Importantly, the results showed a reliable preview effect for each top-up condition, relative to the conjunction condition. That is, the old items were being searched less under preview conditions than when they were presented simultaneously with the search set. Performance tended to be worse in the offset conditions, in comparison with the single-feature search, but this difference was not reliable between top-up previews: There was a main effect of display size $\left[F(2,30)=114.37, M S_{\mathrm{e}}=2,534,855, p<\right.$ $.01]$, but not of condition. Neither was there a reliable condition $\times$ display size interaction or an effect of search slopes. Search was robust to the location changes even when there were no color differences between the preview and the search displays. The carryover from the first preview to its subsequent representation was not based solely on the items' having a different color from those in the search set, facilitating color filtering of the old display.

There are several interesting aspects of these data. One is that they confirm that preview benefits are not contingent on the presence of color differences between the displays (see also Olivers et al., 1999, and Theeuwes, Kramer, \& Atchley, 1998, for prior evidence). Another is that they demonstrate top-up effects that are robust to location/configuration changes and that are not dependent on color segmentation. Given the robustness of the effects with respect to location/configural changes, how do we account for these top-up data? One possibility is that the representation of the old display is ignored under preview conditions by a form of inhibitory tagging applied to individual letters in the old displays. This object-based inhibition remains with the letters even after they have changed their location with the subsequent reexposure of the preview. This would link the effects to so-called object-based inhibition of return (IOR; Tipper, Driver, \& Weaver, 1991), where inhibitory tags are applied to objects irrespective of their spatial location. Maintenance of these inhibitory tags across the previews would prevent attention from returning to the old items when the search displays appear. An alternative is that the encoding of the identities or form of the letters in the original preview primes the encoding of 


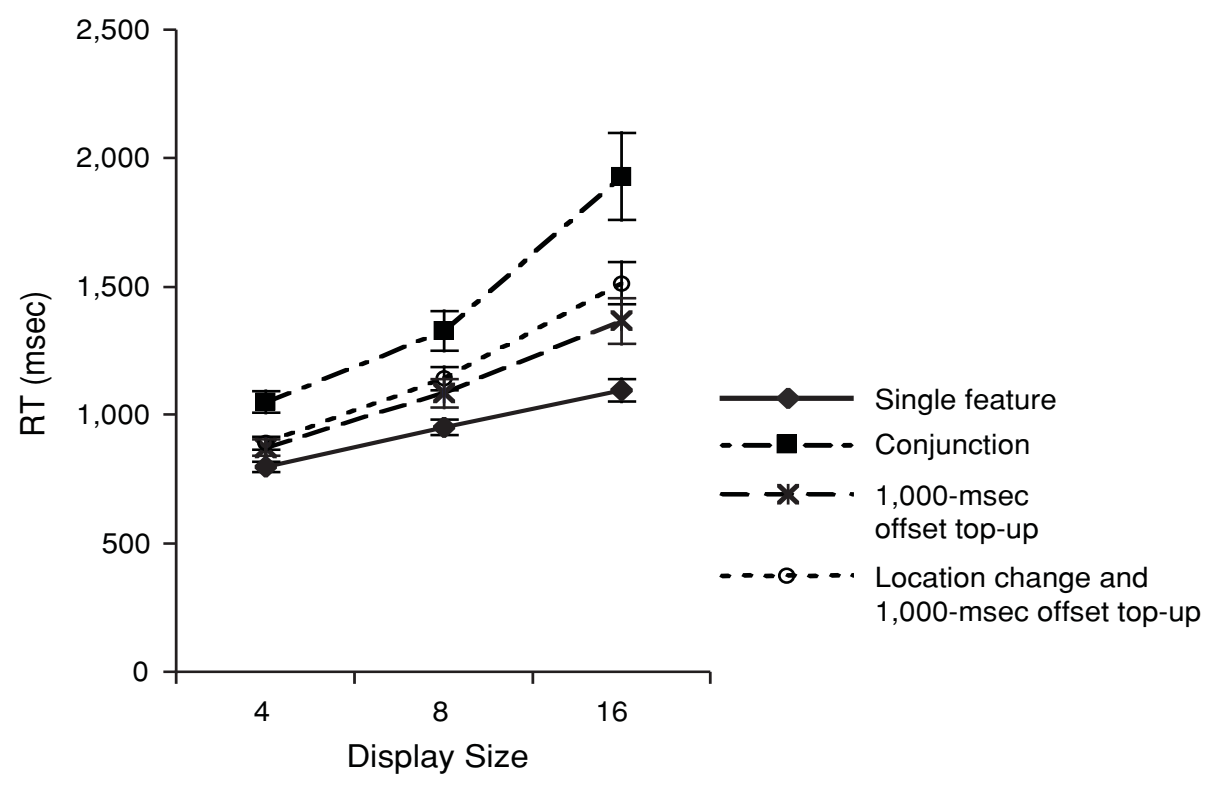

Figure 6. Mean correct reaction times (RTs, in milliseconds) for each condition in Experiment 3. Note that the single-feature condition had half as many items as did the conjunction condition and the final display in the preview condition.

the same letters in the subsequent preview, enabling the preview to be filtered more efficiently than would otherwise be the case (taking place within $150 \mathrm{msec}$, rather than the 400-600 msec that might otherwise be required; cf. Humphreys et al., 2004; Watson \& Humphreys, 1997). On the last view, there may not be inhibition applied to the original preview, but faster inhibitory filtering of the subsequent preview is generated. In Experiment 4, we examined these two possibilities more closely. Here, we used different letters of the alphabet as stimuli in a top-up condition, where the old distractors could re-appear either in their initial locations or in different locations after the offset period. If inhibitory tagging of individual stimuli is responsible, at least a partial preview effect should be found in Experiment 4. If, instead, it is the encoding of a common form of the preview items that is important, no preview effect should occur.

The data can also be used to investigate which mechanism is responsible for the preview effect. A valid preview benefit occurred in both top-up conditions, despite the fact that a $150-\mathrm{msec}$ preview on its own did not produce efficient search (see note 5 and Kunar, Humphreys, \& Smith, 2003, for details); the initial presentation of the old items needed to be present. An onset capture account and a temporal-grouping account in isolation cannot be used to explain these results. However, the data do fit with a visual-marking theory suggesting that information from the initial preview stimuli is carried over or used to prime the re-presented stimuli so that they can be discounted from search.

An alternate account of the data presented in Experiment 3 is one suggesting that the results have emerged due to a form of transient, sensory habituation. This account suggests that when the preview items initially appeared, the visual system became habituated to their onset, so that it was less sensitive to further transients. Thus, when the preview items reonset, the time needed for the transient to decay was less than it would have been if the preview items had not been presented initially. Here, a preview effect could occur, since this increased transient decay rate of the re-presented preview allowed the onset of the new items to more readily capture attention. This was investigated in Experiment 4. If a transient, sensory habituation account holds, a preview effect should still be found in the location change preview in Experiment 4, since the visual system would have again undergone habituation to the initial preview.

\section{EXPERIMENT 4}

\section{Method}

Participants. Fourteen participants ( 3 of them male and 11 female) took part for monetary payment. Their ages ranged from 18 to 50 years (mean age, 27.4 years), and they had normal or correctedto-normal eyesight. All the participants were volunteers from the Boston community.

Stimuli. All the stimuli were produced by Matlab software with the PsychToolbox (Brainard, 1997; Pelli, 1997) and were run on a Macintosh computer. The letters subtended a visual angle of approximately $1.3^{\circ} \times 1.5^{\circ}$ at an observation distance of $57 \mathrm{~cm}$. The search task involved finding either the letter $\mathrm{N}$ or $\mathrm{Z}$ among the other letters taken from the alphabet. (Please note that we omitted the letter W from our distractor set, since it was wider than most of the other letters.) The target was present on every trial. Although this was a small change relative to the "classic" target present-absent responses used by Watson and Humphreys (1997), several other studies have now 
employed similar procedures and have reported similar search functions (e.g., Braithwaite \& Humphreys, 2003).

Design and Procedure. There were four search conditions: (1) a conjunction condition in which both the target and the distractor items appeared simultaneously, ${ }^{6}(2)$ a 150 -msec preview condition in which half the distractor items were previewed $150 \mathrm{msec}$ prior to the onset of the rest of the distractors and the target item, (3) a topup preview condition in which the previews offset and reappeared in their original locations (preview items appeared for $450 \mathrm{msec}$ and offset for $250 \mathrm{msec}$ before reappearing again $150 \mathrm{msec}$ before the rest of the targets and distractors were added), and (4) a top-up preview (using the same timing as above) in which the previews offset but then reappeared in new, previously unoccupied locations. Each of the experimental blocks contained 60 trials ( 20 per display size). The order of blocks was randomized, and the participants were given a practice session before each condition. Each experiment lasted approximately $30 \mathrm{~min}$ in total.

In each condition, a fixation cross appeared on the screen for $1,000 \mathrm{msec}$, followed by either the preview or the full search display (in the conjunction condition). The participants were asked to keep their eyes on the central cross until the second set of stimuli were presented and then to respond to either the $\mathrm{N}$ or the $\mathrm{Z}$ by pressing one of two keys.

\section{Results and Discussion}

Figure 7 shows the mean correct RTs as a function of display size for Experiment 4. The error rates are given in Table 1, and Table 2 shows the search slopes. Error rates were generally low, and since they showed no sign of a speed-accuracy trade-off, they were not examined further. RTs more than three standard deviations away from each condition mean or less than $200 \mathrm{msec}$ were eliminated. This procedure removed $0.6 \%$ of the data.

No location change preview compared with conjunction condition. For the standard top-up preview, there was a preview benefit when the preview condition was compared with the conjunction condition. Here, there were reliable main effects of condition $[F(1,13)=4.68$, $\left.M S_{\mathrm{e}}=163,126, p=.05\right]$ and of display size $[F(2,26)=$ $\left.131.00, M S_{\mathrm{e}}=1,702,311, p<.01\right]$. The condition $\times$ display size interaction also reached significance $[F(2,26)=$ $\left.5.85, M S_{\mathrm{e}}=38,823, p<.01\right]$. There was a greater increase in RTs with increases in display size in the conjunction condition than in the top-up preview, and search slopes showed greater efficiency in the top-up condition than in the conjunction condition $\left[F(1,14)=6.67, M S_{\mathrm{e}}=\right.$ $825, p<.05]$. This again replicates Kunar, Humphreys, and Smith (2003). There was also a benefit for RTs and slopes when the standard top-up was compared with the 150-msec preview: There were reliable main effects of condition $\left[F(1,13)=14.29, M S_{\mathrm{e}}=305,670, p<.01\right]$ and of display size $\left[F(2,26)=125.25, M S_{\mathrm{e}}=1,935,153\right.$, $p<.01]$. The condition $\times$ display size interaction also reached significance $\left[F(2,26)=7.94, M S_{\mathrm{e}}=70,264, p<\right.$ $.01]$. There was a greater increase in RTs with increases in display size in the 150 -msec preview condition than in the top-up preview condition, and search slopes showed greater efficiency in the top-up condition than in the 150msec preview condition $\left[F(1,13)=11.12, M S_{\mathrm{e}}=1,827\right.$, $p<.01]$. Adding an initial presentation of the old items before they offset and reonset for $150 \mathrm{msec}$ produced a benefit in search over and above that produced by just presenting the old stimuli on the screen for $150 \mathrm{msec}$. [In fact, there was no benefit in presenting the old items for only $150 \mathrm{msec}$, in comparison with the conjunction condition. Here, there was a reliable main effect of display size- $F(1,26)=140.63, M S_{\mathrm{e}}=2,453,935, p<.01-$ but not of condition. Neither was there a significant condition $\times$ display size interaction or an effect of slopes.]

Location change preview compared with conjunction condition. In contrast to the results when the preview

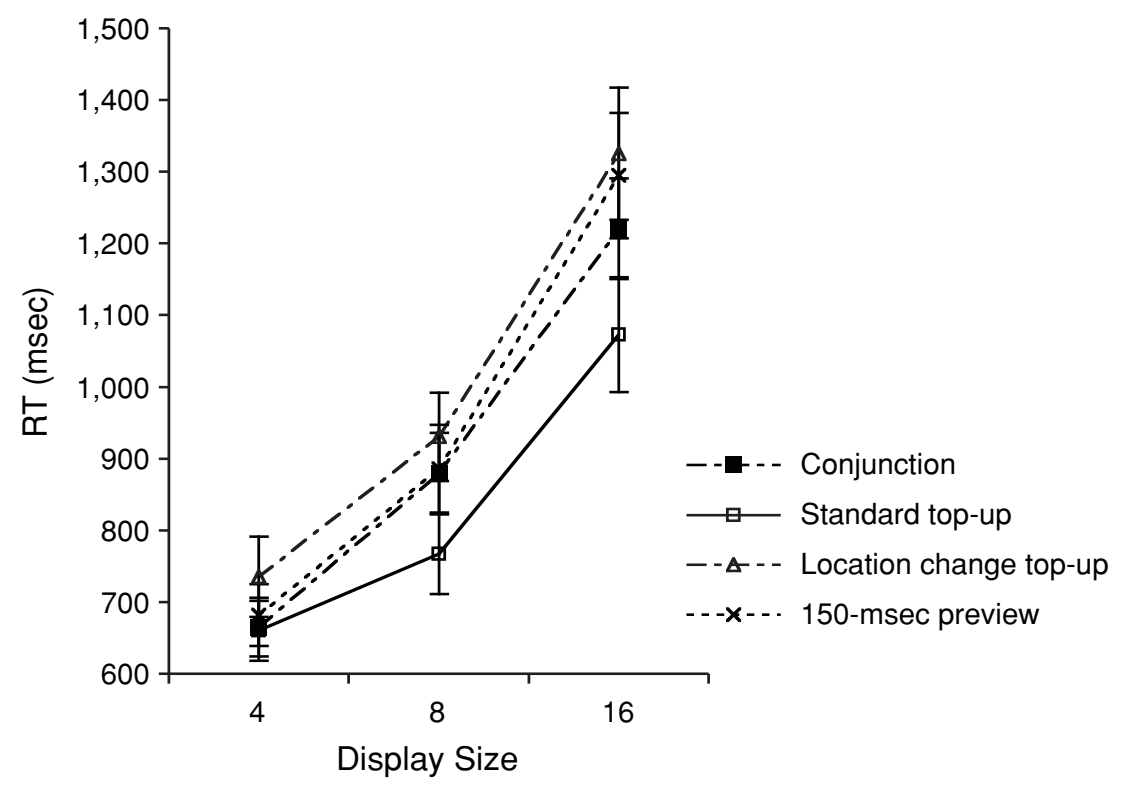

Figure 7. Mean correct reaction times (RTs, in milliseconds) for each condition in Experiment 4. 
items maintained their locations across the initial preview and subsequent top-up displays, there was no search benefit for the top-up location change preview, in comparison with the conjunction condition. There were reliable main effects of condition $\left[F(1,13)=5.75, M S_{\mathrm{e}}=119,470\right.$, $p<.05]$ and of display size $\left[F(2,26)=150.10, M S_{\mathrm{e}}=\right.$ $2,360,012, p<.01]$. However, the condition $\times$ display size interaction did not reach significance. Neither was there any difference in terms of search slopes. There was also no search advantage for the top-up location change preview, relative to the $150-\mathrm{msec}$ preview: There was a reliable main effect of display size $[F(2,26)=115.87$, $\left.M S_{\mathrm{e}}=2,628,513, p<.01\right]$. However, there was no main effect of condition, nor was there a reliable condition $\times$ display size interaction. There was no difference between the search slopes.

The data show that when heterogeneous stimuli were used, a preview effect occurred in the top-up preview only when the old distractors did not change their locations across the offset period (between the initial preview and the top-up). When the old distractors changed positions during the offset period, no preview effect occurred. This was again made apparent when the two top-up previews were compared. Here, there were reliable main effects of condition $\left[F(1,13)=15.29, M S_{\mathrm{e}}=561,801, p<.01\right]$ and of display size $\left[F(2,26)=93.09, M S_{\mathrm{e}}=1,852,089, p<\right.$ $.01]$. The condition $\times$ display size interaction also reached significance $\left[F(2,26)=7.92, M S_{\mathrm{e}}=55,260, p<.01\right]$. There was a greater increase in RTs with increases in display size in the location change preview condition than in the standard top-up preview condition, and search slopes showed greater efficiency in the standard top-up condition than in the location change preview condition $[F(1,13)=$ $\left.11.09, M S_{\mathrm{e}}=1,428, p<.01\right]$. Overall, search was more efficient when the old distractors maintained their position across the offset period than when they moved.

These data give a new insight into search performance under preview conditions, because they suggest that at least two factors may be involved, according to whether the old items have a common form. When the preview items have a common color or form that differs from that of the new search distractors, they continue to be ignored when re-presented in a 150 -msec top-up display even when their locations are changed (Experiments 2 and 3). Previews that share their color with the new items and that have heterogeneous forms can be ignored when the items stay in the same location, but not when they change locations across the offset period (between their first presentation and the top-up period; Experiment 4). These data are consistent with location-based suppression of the old items that operates irrespective of whether the old items have the same form (cf. Watson \& Humphreys, 1997). In addition, when the old items do have a common form, they can be ignored even when they change position across the top-up period. In the last case, the benefit of the preview cannot be the result of location-based suppression. It also seems unlikely that the ability to ignore the preview under the last condition is due to item-based IOR, because that should have occurred even if the heterogeneous distrac- tors moved (Tipper et al., 1991). An alternative account of the benefit with homogenous distractors is that it reflects inhibition of the form information common across the group. Both when the old items remain in the same location across an offset interval and when they move, the old items are deprioritized for search. This would not occur when the old distractors are heterogeneous, since multiple different forms are present. The present findings also cause difficulties for a transient habituation account. If the top-up preview effect arises because the sensitivity of the visual system is reduced when the old items reonset after they have disappeared, a similar preview effect should have occurred in both the standard top-up preview and the location change top-up preview conditions in this experiment. However, this was not the case.

\section{GENERAL DISCUSSION}

We have reported data showing the following.

1. Efficient preview search occurred under top-up conditions when the old items offset for up to $1,000 \mathrm{msec}$ before the subsequent preview (Experiments 1A, 2, and 3).

2. Efficient top-up preview search was disrupted when the old items offset for 2,000 msec. Here, search efficiency was reduced (Experiment 1B).

3. The preview benefit remained when old items changed their initial locations and configuration across the offset period, as long as the old items shared the same form with one another (Experiments 2 and 3).

4. If the old items had a different form with respect to one another, a preview effect occurred if the items stayed in the same location between the initial preview and the top-up period; however, no preview effect occurred if the old items changed their locations across the offset period (Experiment 4).

5. The top-up effect on preview search was not contingent on color differences between the preview and the search displays, even when the old items changed their locations (Experiment 3).

\section{Mechanisms of Preview Search}

These results have important implications for understanding the mechanisms behind preview search.

Attentional capture by new onsets. Consider first the onset capture account of Donk and Theeuwes (2001). This account has difficulty explaining why any top-up effects should occur in preview search, when the presentation of the short 150 -msec preview alone was not sufficient to produce the preview effect (Kunar, Humphreys, \& Smith, 2003; see also Experiment 4 here). Here, the temporal conditions of the short preview must not be adequate to allow onset capture by the search displays. Yet for onset capture to explain the preview effect found in Experiments 2, 3, and 4, this capture effect would have to be reinstated by presenting an earlier preview up to $1 \mathrm{sec}$ before the later displays. There seems to be no reason why this should be the case.

Donk and Verburg (2004) recently found that a preview effect could be shown with only a $50-\mathrm{msec}$ preview pe- 
riod if the onset of the old items was isoluminant to the background display and the new items appeared as onsets. However, if the old items did show a luminance onset, no preview effect was found (similar to our findings with the 150-msec preview alone; see Experiment 4, note 5, and Kunar, Humphreys, \& Smith, 2003). Donk and Verburg suggested that these data give evidence for an attentional capture account of the preview effect. They proposed that the luminance transient of the old items may prevent the luminance of the new items from capturing attention if both the old and the new stimuli are defined by onsets and both are presented in close temporal proximity (e.g., due to suppression of a response to the first onset of the preview). When the old items are isoluminant, there is no such interference on the onset of the search display. Although we agree that attentional capture may play a part in the preview effect, it still cannot explain why presenting and then offsetting the old items prior to the $150-\mathrm{msec}$ preview allows them then to be discounted from search. Instead, perhaps Donk and Verburg's data suggest that in order to be considered searchable (and in turn, discounted from search), old items need to produce a luminance increment to compete strongly with other luminance increments for selection. ${ }^{7}$

Donk and Verburg (2004) also suggested that the top-up effect can be explained by the items in the second presentation having undergone IOR (see Klein, 2000, for a review) and, thus, no longer attracting attention. However, this seems unlikely for a number of reasons. First, IOR may be applied only to approximately 3 items (see Danziger, Kingstone, \& Snyder, 1998; Pratt \& Abrams, 1995). Here, however, 8 items were discounted from search, and other studies have shown that up to 15 items can be discounted under preview conditions (Theeuwes et al., 1998). Second, this does not explain why a preview effect does not occur when the old items reonset with the new (Kunar, Humphreys, Smith, \& Watson, 2003; Watson $\&$ Humphreys, 1997). Here, the old items should still undergo IOR and, thus, be discounted from search. Finally, Olivers, Humphreys, Heinke, and Cooper (2002) had participants serially search through a preview display prior to the new items (plus the target) appearing - conditions producing optimal IOR. However, in contrast to an IOR prediction, this was found to disrupt the preview effect.

Temporal grouping. The temporal-grouping account of preview search encounters similar difficulties. On this view, attention can be applied to each of two groups that are segmented in time (Jiang et al., 2002). Here, we suppose that the short preview before the search display was not sufficient to produce temporal segmentation, so that a preview benefit was prevented (Experiment 4 and note 5; see also Kunar, Humphreys, \& Smith, 2003). But then, how can segmentation, based on temporal cues alone, be reinstated by the much earlier presentation of the top-up preview? More than temporal segmentation and onset capture alone, these data point to the importance of the representation of the old items, which is carried across the offset interval and facilitates the filtering of the old display from search. Nevertheless, even though we sug- gest that temporal grouping cannot provide a complete account of the data, there are some merits to the temporalgrouping account. In particular, the preview search advantage can be eliminated if a preview display offsets and then onsets with the new search display (Watson \& Humphreys, 1997). In this case, temporal grouping between the preview and the search displays appears to override any effects of the representation of the old items. Nevertheless, the effects of this representation do become apparent when temporal grouping is disrupted by using a short presentation of the preview before the search display (as in the top-up procedure here).

Visual marking. A third account of the preview effect suggests that the old items undergo top-down attentional inhibition, known as visual marking (Watson \& Humphreys, 1997). By deprioritizing or inhibiting the old items, new items are prioritized for selection, allowing for efficient search. Alone among the accounts we have considered, the marking account does propose a role for a representation of the old items in preview search. Essentially, inhibition of this representation enables the old items to be filtered from search. The top-up effects from the initial preview are consistent with this. There are a number of aspects of the previewed representation that could be used for filtering. For example, Kunar, Humphreys, Smith, and Hulleman (2003) found that search was disrupted when the old items moved and changed configuration, in comparison with when they moved but there was no configural change, prior to the onset of the new. In addition, evidence from probe dot procedures have indicated that there is inhibition applied to the locations of the old items (so that probes at those locations are difficult to detect; Olivers \& Humphreys, 2002; Watson \& Humphreys, 2000). The last proposal is also supported by the data presented here, where we show that under top-up conditions, a heterogeneous group of old items can be ignored, provided that they remain in the same locations across an offset period. The lack of impact of these items would be expected if their locations were suppressed. Along with configural and location information, the present data additionally suggest that object properties can also be useful when stimuli are filtered. ${ }^{8}$

There are two possible ways that object-based filtering could occur. Either there is direct inhibition of individual items in the original preview, which is carried over an interval of at least $1 \mathrm{sec}$ to affect the subsequent preview (akin to object-based IOR; Tipper, Weaver, Cameron, Brehaut, \& Bastedo, 1991), or the initial preview facilitates the encoding and inhibition of the subsequent preview. The first account raises problems. We used preview displays with up to eight items, so on this account, object-based inhibition would have to apply to up to eight items. Although possible, we know of no other converging evidence to indicate that this could occur. Furthermore, our data show that if the preview stimuli are heterogeneous, they are not discounted from search if they reappear in a new location. If they were individually marked, a benefit in search should have been seen. Instead, the preview effect is more likely to result from marking based on object form. Since 
the old items belong to a homogeneous distractor group, the visual system may be able to "tag" any in-group item (e.g., a blue $\mathrm{H}$ or an upright $\mathrm{T}$ ) as unimportant. Subsequent repetition of these items would, therefore, remain inhibited, regardless of location change. Naturally, if these items had not been previously inhibited, search would not be efficient (i.e., in the 150-msec preview; Kunar, Humphreys, \& Smith, 2003; see also note 5). This also explains why no preview effect occurred when the preview items were heterogeneous and changed location across the offset period: Here, the preview set could not be marked or discounted on the basis of common form.

This idea is similar to that of negative priming (see Fox, 1995, for a review). Here, repeated presentations of previously ignored items show an increase in RT when they are re-presented as target items. Although Watson and Humphreys (1997) suggested that negative priming could not account for the preview effect, there may be a benefit in comparing these two mechanisms. Originally, negative priming was discounted as a mechanism for preview search, since the preview effect disappeared if the old items offset before reappearing simultaneously with the new (Watson \& Humphreys, 1997). Inhibition in negative priming, on the other hand, needs to be carried across an offset period. However, more recent studies (including the experiments presented here) have shown that the preview effect can be carried across offset periods (Kunar, Humphreys, \& Smith, 2003), providing that the old items do not reonset with the new. Furthermore, negative priming is suggested to have a "shelf-life" of 2,000 msec (Neill \& Valdes, 1992; although see Tipper et al., 1991, who found effects lasting up to $6 \mathrm{sec}$ ), which corresponds with our findings in Experiment 1B. Other effects consistent with a negative-priming effect have come from studies of negative carryover effects across trials. For example, Olivers and Humphreys (2002) found a carryover effect from an ignored preview on search of a target display on a subsequent trial, when the target display carried the color of the ignored preview. On the basis of these similarities, it may be tempting to suggest that preview search and negative priming are one and the same effect. One crucial difference, however, remains: Negative priming persists when the previous ignored distractor reonsets alongside the new item; the preview effect does not (Kunar, Humphreys, Smith, \& Watson, 2003; Watson \& Humphreys, 1997). In preview search, this cooccurrence of old and new removes any previous inhibition. Despite this, it may be useful for further studies to investigate how negative priming and preview search interact.

In sum, there may be different mechanisms of filtering old items in preview search. Which one is dominant may depend on task demands. Prior research has shown that location (Olivers \& Humphreys, 2002; Watson \& Humphreys, 2000), configuration (Kunar, Humphreys, Smith, \& Hulleman, 2003), and even color-based inhibition (Braithwaite \& Humphreys, 2003; Olivers \& Humphreys, 2002) all play a role. The present results show that when the old items have a common form, object-based inhibition or priming may be strongly weighted in search. Fur- ther studies should be performed to investigate how these various types of marking mechanisms interact.

\section{REFERENCES}

Brainard, D. H. (1997). The Psychophysics Toolbox. Spatial Vision, 10, 443-446.

Braithwaite, J. J., \& Humphreys, G. W. (2003). Inhibition and anticipation in visual search: Evidence from effects of color foreknowledge on preview search. Perception \& Psychophysics, 65, 213-237.

Braithwaite, J. J., Humphreys, G. W., Watson, D. G., \& Hulleman, J. (2005). Revisiting preview search at isoluminance: New onsets are not necessary for the preview advantage. Perception \& Psychophysics, 67, 1214-1228.

DanZiger, S., Kingstone, A., \& Snyder, J. J. (1998). Inhibition of return to successively stimulated locations in a sequential visual search paradigm. Journal of Experimental Psychology: Human Perception \& Performance, 24, 1467-1475.

Donk, M., \& Theeuwes, J. (2001). Visual marking beside the mark: Prioritizing selection by abrupt onsets. Perception \& Psychophysics, 63, 891-900.

Donk, M., \& Verburg, R. C. (2004). Prioritizing new elements with a brief preview period: Evidence against visual marking. Psychonomic Bulletin \& Review, 11, 282-288.

Fox, E. (1995). Negative priming from ignored distractors in visual selection: A review. Psychonomic Bulletin \& Review, 2, 145-173.

Humphreys, G. W., Kyllingsbaek, S., Watson, D. G., Olivers, C. N. L., Law, I., \& Paulson, O. (2004). Parieto-occipital areas involved in efficient filtering in search: A time course analysis of visual marking using behavioural and functional imaging procedures. Quarterly Journal of Experimental Psychology, 57A, 610-635.

Humphreys, G. W., Watson, D. G., \& Joliceur, P. (2002). Fractionating visual marking: Dual-task decomposition of the marking state by timing and modality. Journal of Experimental Psychology: Human Perception \& Performance, 28, 640-660.

JiAng, Y., Chun, M. M., \& Marks, L. E. (2002). Visual marking: Selective attention to asynchronous temporal groups. Journal of Experimental Psychology: Human Perception \& Performance, 28, 717-750.

KLEIN, R. M. (2000). Inhibition of return. Trends in Cognitive Sciences, 4, 138-147.

Kunar, M. A., Humphreys, G. W., \& Sмith, K. J. (2003). History matters: The preview benefit in search is not onset capture. Psychological Science, 14, 181-185.

Kunar, M. A., Humphreys, G. W., Smith, K. J., \& Hulleman, J. (2003). What is "marked" in visual marking? Evidence for effects of configuration in preview search. Perception \& Psychophysics, 65, 982-996.

Kunar, M. A., Humphreys, G. W., Smith, K. J., \& Watson, D. G. (2003). When a reappearance is old news: Visual marking survives occlusion. Journal of Experimental Psychology: Human Perception \& Performance, 29, 185-198.

NeILl, W. T., \& VAldes, L. A. (1992). Persistence of negative priming: Steady state or decay? Journal of Experimental Psychology: Learning, Memory, \& Cognition, 18, 565-576.

Olivers, C. N. L., \& HumphreYs, G. W. (2002). Visual marking under attentional blink conditions: More evidence for top-down limited capacity inhibition. Journal of Experimental Psychology: Human Perception \& Performance, 28, 22-42.

Olivers, C. N. L., Humphreys, G. W., Heinke, D., \& Cooper, A. C. G. (2002). Prioritization in visual search: Visual marking is not dependent on a mnemonic search. Perception \& Psychophysics, 64, 540-560.

Olivers, C. N. L., Watson, D. G., \& Humphreys, G. W. (1999). Visual marking of locations and feature maps: Evidence from within-dimension defined conjunctions. Quarterly Journal of Experimental Psychology, 52A, 679-715.

Pelli, D. G. (1997). The VideoToolbox software for visual psychophysics: Transforming numbers into movies. Spatial Vision, 10, 437-442.

Pratt, J., \& Abrams, R. A. (1995). Inhibition of return to successively cued spatial locations. Journal of Experimental Psychology: Human Perception \& Performance, 21, 1343-1353.

Theeuwes, J., Kramer, A. F., \& Atchley, P. (1998). Visual marking of old objects. Psychonomic Bulletin \& Review, 5, 130-134. 
Tipper, S. P., Driver, J., \& Weaver, B. (1991). Object-centred inhibition of return of visual attention. Quarterly Journal of Experimental Psychology, 43A, 289-298.

Tipper, S. P., Weaver, B., Cameron, S., Brehaut, J., \& Bastedo, J. (1991). Inhibitory mechanisms of attention in identification and localization tasks: Time course and disruption. Journal of Experimental Psychology: Learning, Memory, \& Cognition, 17, 681-692.

Watson, D. G., \& Humphreys, G. W. (1997). Visual marking: Prioritizing selection for new objects by top-down attentional inhibition of old objects. Psychological Review, 104, 90-122.

WATSOn, D. G., \& Humphreys, G. W. (2000). Visual marking: Evidence for inhibition using a probe-dot detection paradigm. Perception \& Psychophysics, 62, 471-481.

YANTIS, S., \& Gibson, B. (1994). Object continuity in apparent motion and attention. Canadian Journal of Experimental Psychology, 48, 182-204.

\section{NOTES}

1. Similar effects were found by Jiang et al. (2002), who showed that a preview benefit could be obtained if a $107-\mathrm{msec}$ preview display was presented, providing that an initial (but not identical) preview display had been presented for $1,000 \mathrm{msec}$ previously.

2. The offset intervals were sufficiently long to ensure that there was minimal apparent motion when the preview letters changed positions.

3. Using Ts in different orientations allowed the participants to search for the target in the absence of a color cue - something that would have been impossible if the previous displays of As and $\mathrm{Hs} \mathrm{had} \mathrm{been} \mathrm{used} \mathrm{(i.e.,}$ if all the items were the same color, the participants would not be able to distinguish the target $\mathrm{H}$ from the distractor $\mathrm{H}$ ). Both Kunar, Humphreys, Smith, and Hulleman (2003) and Olivers et al. (1999) found a valid preview effect with rotated $\mathrm{T}$ stimuli.

4. Although this condition was not a single-feature task in the strict sense of the word (since the target could not be identified on the basis of one feature in particular), its purpose was similar to that of the singlefeature conditions in the experiments above (i.e., it provided a measurement of search rate with only half the display present). Therefore, we will continue to use this term for simplicity.

5. A separate experiment was conducted, using the stimuli in Experiment 3 , to show that any preview benefit was not due just to the 150msec secondary presentation. Eleven participants ( 2 of them male and 9 female; mean age, 27.1 years) took part in a conjunction condition, the 1,000 -msec offset top-up preview, and a preview condition in which the old distractors were presented only for $150 \mathrm{msec}$. The number of trials was doubled, per display size, to show that the same result occurred regardless of trial number. As was expected, RTs across display size in the top-up condition were reliably shorter than those in both the conjunction condition $\left[F(2,20)=4.62, M S_{\mathrm{e}}=71,344, p<.05\right]$ and the $150-\mathrm{msec}$ preview condition $\left[F(2,20)=5.63, M S_{\mathrm{e}}=91,570, p<.05\right]$. The 150 msec preview condition did not differ from the conjunction condition across display size. Analyses on search slopes showed the same pattern of results (mean slopes: conjunction $=66 \mathrm{msec} /$ item; 1,000-msec offset top-up $=47 \mathrm{msec} /$ item; 150 - $\mathrm{msec}$ preview $=68 \mathrm{msec} /$ item). The preview benefit in the top-up condition was not due just to the $150-\mathrm{msec}$ re-presentation of the old items.

6. Again, although this was not a conjunction condition in the strictest sense of the word, we will continue to use this terminology for simplicity. Note that no single-feature condition was used in this experiment. Instead, we used the conjunction search as our baseline to probe for the preview effect.

7. Donk and Verburg (2004) did not include the equivalent of a conjunction baseline in their study, so they could not assess whether the isoluminant distractors would have had any impact on search, even if they appeared simultaneously with the onset items. However, Braithwaite, Humphreys, Watson, and Hulleman (2005) have shown that isoluminant items have minimal impact on search for luminance-defined targets, even when they all appear together. Hence, there may not be anything special in Donk and Verburg's finding that isoluminant distractors also have no impact when they precede luminance-defined search items by $150 \mathrm{msec}$.

8. Object-based filtering is an additional marking mechanism separate from color, location, and configural marking. The different marking mechanisms are used to complement each other in search, depending on task demands. If location, color, and configuration are not consistent across previews, marking based on object properties should be optimal. It may also be the case that object-based marking may be affected by configural and location changes. This may explain the small numeric difference (although this was not significant) between the location change preview and the no location change preview in Experiment 3.

(Manuscript received July 16, 2003; revision accepted for publication April 24, 2005.) 